\title{
Tinjauan Fiqh Muamalah terhadap Pelaksanaan Arisan Kurban Idul Adha di Mesjid Al-Hadi Sholihin Cibaduyut Kecamatan Bojongloa Kidul Kota Bandung
}

\author{
Shinta oktapiani, shindu Irawan, YayatRahmat Hidayat \\ Program Studi Hukum Ekonomi Syariah, Fakultas Syariah, Universitas Islam Bandung \\ Jl. Tamansari No. 140116 \\ shintaokta1995@gmail.com, shinduirwansyah@gmailcom,yayatrahmathidayat@unisba.ac.id
}

\begin{abstract}
Abstarct-As time goes on, many use the practice of buying and Sacrifice Worship Is One Of Taqarrub Worship, The Word Sacrifice Itself Comes From The Word "Qaruba" Which Has A Close Meaning. Muslim Believers Manifest The Qur'anic Verses Al-Kausar Verses 1-3 That Explain The Pleasure That Allah SWT Will Give To His Servants Who Want To Pray And Sacrifice. Reality On The Ground Shows That The Cost Of Purchasing Sacrificial Animals Is Considered Light For The Economic Community And Above. While The Middle Economic Community Below Feels That The Sacrifice Is Still Quite High. Then A Sacrificial Gathering Was Formed At Al-Hadi Sholihin Cibaduyut Mosque, Bojongloa District, Kidul, Bandung. From The Background Of This Problem There Are A Number Of Issues Discussed Including: 1) What Is The Concept Of Arisan In Islam? 2) How Is The Sacrifice Arisan Held At Al-Hadi Sholihin Cibaduyut Mosque In Bandung? 3) What Is The Review Of Islamic Law On Sacrifice Arisan At Al-Hadi Sholihin Cibaduyut Mosque In Bandung?
\end{abstract}

This Research Is A Qualitative Field Research By Collecting Data Through Interviews And Documentation. The Data Management Technique Uses Editing, Organizing And Research Findings. The Data Analysis Used In This Study Is The Inductive Analysis Method.

The Final Conclusions Of This Study Are: 1) Legal Arisan May Be Due To The Fact That Arisan Is An Ariyah Contract, Which Is A Loan Agreement, To Be Exact, An Al-Qard / AlQiradh Contract, Namely Accounts Payable And Credit. It Is Also A Form Of Contract Based On The Principle Of Taawun, That Is, Please Help. 2) The Implementation Of A Sacrificial Gathering At Al-Hadi Sholihin Cibaduyut Mosque In Bojongloa Kidul Subdistrict Based On The Formation Of The Contract Through Debts Which In Muamalah Fiqh Is Known As The Qard Contract Which Is Performed Orally Then Strengthened By Writing.3) Arisan Sacrifice Of Al-Hadi Sholihin Cibaduyut Mosque. Bojongloa Kidul Sub-District Is Legal And Permissible. The Contract In The Sacrifice Sacrifice Of Al-Hadi Sholihin Cibaduyut Mosque, Bojongloa Kidul Subdistrict Uses A Credit Agreement (Qard), This Contract Has Fulfilled The Pillars And Qardh Conditions, So It May Be Done Because It Is Not Contrary To Islamic Law.

Keywords-Islamic Law, Sacrifice Arisan
Abstrak - Ibadah Kurban Merupakan Salah Satu Ibadah Taqarrub, Kata Kurban Sendiri Berasal Dari Kata "Qaruba" Yang Mempunyai Arti Dekat. Umat Islam Yang Beriman Memanisfastasikan Ayat Alquran Surat Al-Kausar Ayat 1-3 Yang Menerangkan Tentang Kenikmatan Yang Akan Diberikan Oleh Allah SWT Pada Hambanya Yang Mau Menjalankan Sholat Dan Berkurban. Realita Di Lapangan Menunjukan Bahwa Biaya Pembelian Hewan Kurban Dirasa Ringan Bagi Kalangan Ekonomi Ke Atas. Sedangkan Masyarakat Ekonomi Menengah Kebawah Merasa Ibadah Kurban Masih Cukup Tinggi. Maka Terbentuklah Arisan Kurban Di Mesjid Al-Hadi Sholihin Cibaduyut Kecamatan Bojongloa Kidul Kota Bandung. Dari Latar Belakang Masalah Tersebut Terdapat Suatu Permasalahan Yang Dibahas Diantaranya : 1) Bagaimana Konsep Arisan Dalam Islam ? 2) Bagaimana Pelaksanaan Arisan Kurban Di Mesjid Al-Hadi Sholihin Cibaduyut Kota Bandung ? 3) Bagaimana Tinjauan Hukum Islam Terhadap Arisan Kurban Di Mesjid Al-Hadi Sholihin Cibaduyut Kota Bandung ?

Penelitian Ini Merupakan Penelitian Lapangan Kualitatif Dengan Pengumpulan Data Melalui Interview Dan Dokumentasi. Adapun Teknik Pengelolaan Data Menggunakan Teknik Editing, Organizing Dan Penemuan Hasil Riset. Adapun Analisi Data Yang Digunakan Dalam Penelitian Ini Adalah Metode Analisa Induktif.

Kesimpulan Akhir Dari Penelitian Ini Adalah : 1)Arisan Hukumnya Boleh Karena Pada Hakikatnya Arisan Merupakan Akad Ariyah, Yaitu Akad Pinjam Meminjam Lebih Tepatnya Akad Al-Qard/Al-Qiradh Yaitu Utang Piutang. Selain Itu Juga Merupakan Bentuk Akad Yang Didasarkan Pada Prinsip Taawun Yaitu Tolong Menolong. 2)Pelaksanaan Arisan Kurban Di Mesjid Al-Hadi Sholihin Cibaduyut Kecamatan Bojongloa Kidul Berdasarkan Pembentukan Akadnya Melalui UtangPiutang Yang Mana Dalam Fiqih Muamalah Dikenal Dengan Akad Qard Yang Dilakukan Secara Lisan Kemudian Dikuatkan Dengan Tulisan.3) Arisan Kurban Mesjid Al-Hadi Sholihin Cibaduyut Kecamatan Bojongloa Kidul Sah Dan Boleh Dilaksanakan. Akad Dalam Arisan Kurban Mesjid Al-Hadi Sholihin Cibaduyut Kecamatan Bojongloa Kidul Menggunakan Akad Utang Piutang (Qard), Akad Ini Sudah Memenuhi Rukun Dan Syarat Qardh , Jadi Boleh Dilakukan Karena Tidak Bertentangan Dengan Hukum Islam.

Kata Kunci-Hukum Islam, Arisan Kurban 


\section{Pendahuluan}

Manusia Pada Hakekatnya Diciptakan Di Dunia Ini Untuk Beribadah Kepada Allah SWT. Salah Satunya Ialah Berkurban Pada Hari Raya Idul Adha. Di Dalam Alquran Maupun Hadist Menjelaskan Tentang KetentuanKetentuan Tersebut. Berkurban Juga Dapat Dikatakan Sebagai Bentuk Rasa Syukur Atas Apa Yang Telah Diberikan Kepada Allah SWT Dan Dapat Melatih Agar Peduli Pada Sesama.1Menyembelih Hewan Kurban Pada Hari Raya Idul Adha Merupakan Amal Shalih Yang Paling Utama, Karena Maksud Terpenting Dalam Berkurban Adalah Agar Dapat Mendekatkan Diri Kepada Allah SWT. Ibadah Kurban Bukan Sekedar Persembahan Untuk Meningkatkan Kualitas Spiritual Seseorang Dan Bukan Hanya Cara Untuk Memperoleh Kepuasan Batin. Bukan Juga Kesempatan Bagi Orang Kaya Untuk Menunjukan Kesolehan Dengan Harta Yang Dimiliki. Dengan Ibadah Kurban Seorang Mukmin Memperkuat Kepekaan Sosialnya. Inti Kurban Terletak Pada Individu Seseorang Sebagai Makhluk Sosial. 2

Berbagai Macam Cara Yang Dapat Ditempuh Masyarakat Agar Dapat Berkurban, Baik Secara Mandiri Maupun Secara Kolektif. Pelaksanaan Secara Mandiri Biasanya Membeli Dan Langsung Disembelih Di Sekitar Rumah Lalu Menyewa Jasa Penyembelihan Kurban. Sedangkan Pelaksanaan Secara Koletif Dapat Ditemui Pada Lembaga Pendidikan (Sekolah), Lembaga Keuangan Yang Menyediakan Simpanan Kurban, Organisasi Keagamaan, Elemen Masyarakat, Yayasan Atau Masjid Yang Menawarkan Jasa Untuk Berkurban Bagi Masyarakat Muslim Yang Berniat Untuk Melaksanakan Ibadah Kurban. Berkurban Dari Hasil Arisan Pada Dasarnya Tidak Dilarang. Hanya Saja Bagi Anggota Arisan Yang Telah Berqurban Tetap Mempunyai Kewajiban Membayar Arisan Bagi Anggota Lainnya. Sedangkan Kurban Dengan Cara Urunan (Patungan) Dianggap Sebagai Bentuk Latihan Berkurban, Yang Bernilai Shadaqah.3 Mereka Dapat Dikategorikan Sebagai Orang Yang Belum Mampu Dan Baru Dianggap Latihan Berkurban.

Arisan Kurban Idul Adha Di Mesjid Al-Hadi Sholihin Cibaduyut Kota Bandung Dikelola Oleh Para Pengurus Masjid Atau Pengurus Lingkungan Setempat. Para Pengurus Masjid Atau Pengurus Lingkungan Setempat Itu Lalu Membentuk Kepanitiaan Untuk Mengelola, Mengurus Dan Merawat Hewan Kurban Tersebut. Namun Pada Praktiknya Setelah Pembayaran Arisan Selesai Panitia Arisan Kurban Idul Adha Meminta Uang Tambahan.

Dalam Alquran, Setidaknya Ada 2 (Dua) Istilah Yang Berhubungan Dengan Perjanjian, Yaitu Al-Aqdu (Akad) Dan Al-Ahdu (Janji). Pengertian Akad Secara Bahasa
Adalah Ikatan, Mengikat. Dikatakan Ikatan (Al-Rabth) Maksudnya Adalah Menghimpun Atau Mengumpulkan Dua Ujung Tali Dan Mengikatkan Salah Satunya Pada Yang Lainnya Hingga Keduanya Bersambung Dan Menjadi Seutas Tali Yang Satu.

Istilah Ini Terdapat Dalam QS. Ali Imron Ayat 76

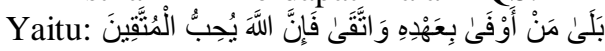

Artinya: "Siapa Sebenarnya Yang Menepati Janji Yang Dibuatnya Dan Bertaqwa, Maka Sesungguhnya Allah Menyukai Orang-Orang Yang Bertaqwa."4

Tujuan Dari Penelitian Ini Adalah Sebagai Berikut :

1. Untuk Mengetahui Bagaimana Konsep Arisan Dalam Islam

2. Untuk Mengetahui Bagaimana Pelaksanaan Arisan Kurban Di Mesjid Al-Hadi Sholihin Cibaduyut Kota Bandung

3. Untuk Mengetahui Tinjauan Hukum Islam Terhadap Pelaksanaan Arisan Kurban Di Mesjid Al-Hadi Sholihin Cibaduyut Kota Bandung

\section{LANDASAN TEORI}

Arisan Adalah Kegiatan Pengumpulan Uang Atau Barang Yang Bernilai Sama Oleh Beberapa Orang, Kemudian Diundi Di Antara Mereka Untuk Menentukan Siapa Yang Memperolehnya. Undian Tersebut Dilaksanakan Secara Berkala Sampai Semua Anggota Memperolehnya. 5 Ada Beberapa Unsur Dalam Arisan, Pertama Yaitu Pertemuan Yang Diadakan Secara Rutin Dan Berkala, Kemudian Pengumpulan Uang Oleh Setiap Anggota Dengan Nilai Yang Sama, Dan Pengundian Uang Untuk Menentukan Siapa Anggota Yang Mendapatkan Arisan Tersebut, Kedua Yaitu Pengumpulan Uang Oleh Setiap Anggota Dengan Nilai Yang Sama Dalam Setiap Pertemuan, Ketiga Yaitu Penyerahan Uang Yang Terkumpul Kepada Pemenang Yang Ditentukan Melalui Pengundian. Jika Dilihat Dari Unsur-Unsur Tersebut, Maka Tidak Ada Hal Yang Melanggar Syariat Dalam Bermuamalah.

Menurut KH.Munawir (Ketua Komisi Fatwa MUI Lampung) Menyatakan Bahwa Pada Dasarnya Arisan Hukumnnya Adalah Boleh Karena Pada Hakikatnya Arisan Meru[Akan Akad Ariyah, Yaitu Akad Pinjam Meminjam, Lebih Tepatnya Akad Al-Qard/Al-Qiradh Yaitu Utang Piutang. Selain Itu Juga Merupakan Bentuk Akad Yang Didasarkan Pada Prinsip Taawun Yaitu Tolong Menolong. Karena Dengan Arisan, Suatu Maksud Tertentu Kurban Dan Akikah Dapat Dicapai Dengan Cara Arisan. Meskipun Seseorang Secara Langsung Belum Mempunyai Biaya Untuk Kurban Dan Akikah Sebelum Memenangkan Undian Arisan Tersebut. Dilihat Dari Sisi Lain, Arisan Juga Merupakan Bentuk Tabungan, Dimana Cicilan Tabungan Dalam Bentuk Setoran Atau Arisan Menjadi 
Tabungan Dirinya Yang Keseluruhan Dapat Diambil Olehnya Ketika Mendapatkan Giliran Atau Undian. Walapun Demikian, Dalam Arisan Harus Memperhatikan Beberapa Hal, Yaitu : Terhindar Dari Unsur Maisir (Judi), Riba (Bunga/Kelebihan Yang Dipersyaratkan), Dan Gharar (Ketidak Jelasan). Atas Dasar Ini Maka Dalam Arisan Harus Dipenuhi Unsur Keadilan Atau Kesamaam Dalam Hal Iuran Yang Dikumpulkan Dan Keadilan Memperoleh Undian. ${ }^{6}$

Kata Akad Berasal Dari Bahsa Arab Al-Aqad Yang Secara Etimologi Berarti Perikatan, Perjanjian, Dan Permufakatan (Al-Ittifaq). Secara Terminologi Fiqh, Akad Didefinisikan Dengan Pertalian Ijab (Pernyataan Melakukan Ikatan) Dan Kabul (Pernyataan Menerima Ikatan) Sesuai Dengan Kehendak Syariat Yang Berpengaruh Terhadap Objek Perikatan. ${ }^{7}$ Dalam Pengertian Fuqaha' Rukun Adalah : Asas, Sendi Atau Tiang. Yaitu Sesuatu Yang Menentukan Sah (Apabila Dilakukan) Dan Tidaknya (Apabila Ditinggalkan) Suatu Pekerjaan Tertentu Dan Sesuatu Itu Termasuk Di Dalampekerjan Itu. Seperti Ruku Dan Sujud Merupakan Sesuatu Yang Menentukan Sah Atau Tidaknya Shalat, Keduanya Merupakan Bagian Yang Tak Terpisahkan Dari Perbuatan "Shalat". Dalam Mu'amalah, Seperti: Ijab Dan Qabul Dan Orang Yang Menyelenggarakan Akad Tersebut. Menurut Jumhur Ulama Rukun Akad Ada Tiga Yaitu Aqid (Orang Yang Menyelenggarakan Akad Seperti Penjual Dan Pembeli), Harga Dan Barang Yang Ditransaksikan (Ma'qud Alaih) Dan Shighatul' Aqd (Bentuk Ucapan Akad), Syarat Terjadinya Akad Adalah Segala Sesuatu Yang Disyaratkan Untuk Terjadinya Akad Secara Syara'. Jika Tidak Memenuhi Syarat Tersebut Akad Menjadi Batal.

Utang Piutang Merupakan Perjanjian Antara Pihak Yang Satu Dengan Pihak Yang Lainnya Dan Objek Yang Diperjanjikan Pada Umumnya Adalah Uang, Kedudukan Pihak Yang Satu Sebagai Pihak Yang Memberikan Pinjaman Sedangkan Pihak Yang Lain Menerima Pinjaman Uang, Uang Yang Di Pinjam Akan Dikembalikan Dalam Jangka Waktu Tertentu Sesuai Dengan Yang Di Perjanjikan. ${ }^{8}$ Qardh Merupakan Suatu Perbuatan Baik Untuk Dilakukan. Bahkan Qardh Disunnahkan Bagi Muqridh (Kreditur/Pemberi Pinjaman). Seperti Halnya Jual Beli Rukun Qardh Juga Diperselisihkan Oleh Para Fuqaha. Menurut Hanafiah, Rukun Qardh Adalah Ijab Dan Qabul.

Dalam Kamus Besar Bahasa Indonesia, Kata Kurban Berarti Mempersembahkan Kepada Tuhan (Seperti BiriBiri, Sapi, Unta Yang Disembelih Pada Hari Raya Lebaran Haji). ${ }^{9}$ Kata Kurban Dalam Bahasa Indonesia Adalah Terjemahan Dari Bahasa Arab. Dalam Penelusuran Penulis
Ditemukan Tiga Buah Kata Yang Mempunyai Pengertian Qurban, Yaitu: An-Nahr, Qurban, Dan Udhiyah. Kata AnNahr Yang Berarti Kurban Hanya Sekali Terdapat Dalam Alquran Dalam Surat Al-Kautsar Dengan Menggunakan Bentuk Amr Yaitu Inhar. Terampil Dari Kata Nahr Yang Dari Segi Bahasa Berarti Dada Sekitar Tempat Untuk Meletakan Kalung. Jika Dikatakan Nahrtuhu Maka Maknanya Saya Mengenai Dada Dalam Arti Menyembelihnya

\section{HASIL PENELITIAN DAN ANALISA PEMBAHASAN}

Di Dalam Arisan Kurban Terdapat Unsur-Unsur Yang Harus Terpenuhi Karena Unsur-Unsur Itulah Yang Akan Membentuk Suatu Tindakan Hukum. Bila Unsur-Unsur Itu Belum Terpenuhi Maka Tindakan Atau Perbuatan Tersebut Juga Belum Merupakan Suatu Tindakan Hukum Yang Sempurna. Unsur-Unsur Yang Ada Di Dalam Arisan Kurban Antara Lain :Adanya Anggota Arisan Kurban, Adanya Pengurus Atau Pengelola Arisan Kurban, Adanya Objek Atau Barang Yang Diakadkan, Dalam Hal Ini Objek Arisan Adalah Berupa Uang Yang Digunakan Untuk Biaya Pembelian Hewan Kurban Dan Sighat Atau Akad Yang Menunjukan Kebolehan Atau Keikhlasan Dari MasingMasing Anggota Dalam Melakukan Arisan Kurban Di Mesjid Al-Hadi Sholihin Cibaduyut Kecamatan Bojongloa Kidul

Dari Analisis Di Atas Penulis Menyimpulkan Bahwa Akad Dan Mekanisme Arisan Kurban Mesjid Al-Hadi Sholihin Cibaduyut Kecamatan Bojongloa Kidul Sah Dan Boleh Dilaksanakan. Akad Dalam Arisan Kurban Mesjid Al-Hadi Sholihin Cibaduyut Kecamatan Bojongloa Kidul Menggunakan Akad Utang Piutang (Qard), Akad Ini Sudah Memenuhi Rukun Dan Syarat Qardh, Jadi Boleh Dilakukan Karena Tidak Bertentangan Dengan Hukum Islam.

Dilihat Dari Syarat Sah Akad Qardh, Arisan Qurban Di Mesjid Al-Hadi Sholihin Cibaduyut Kota Bandung Menggunakan Akad Qardh Sebagai Akad Untuk Keperluan Utang Piutang. Syarat Sah Akad Qardh Ada Tiga Yaitu: Pertama, Utang-Piutang Merupakan Sebuah Transaksi (Akad), Maka Harus Dilaksanakan Melalui Ijab Qabul Yang Jelas, Sebagaimana Jual-Beli Dengan Lafadz Qardh Atau Yang Sepadan Dengannya. Kedua, Harta Benda Yang Menjadi Obyeknya Harus Mal-Mutaqawwim Atau Harta Yang Bernilai. Ketiga, Akad Utang-Piutang Tidak Boleh Dikaitkan Dengan Suatu Persyaratan Di Luar Utang-Piutang Itu Sendiri Yang Mengutangkan Pihak Munqarid (Pihak Yang Mengutangi).

Sedangkan Dalam Syarat Sah Akad Qardh Dalam Praktik Arisan Kurban Di Mesjid Al-Hadi Sholihin Cibaduyut Kota Bandung Adalah Sah Dimana Syarat Sah Akad Qardh Tepenuhi. Rukun Ma'qud Alaih Yaitu Harus Yang Bernilai, Hewan Kurban Yang Menjadi Obyek Akad Merupakan Sesuatu Yang Bernilai Dan Mempunyai Manfaat Tersendiri. Rukun Sighat (Ijab Dan Qabul) Adalah Tercapainya Kesepakatan. Dalam Praktik Arisan 
Kurban Di Mesjid Al-Hadi Sholihin Cibaduyut Kota Bandung Melakukan Sighat (Ijab Dan Qabul) Terlebih Dahulu Dan Mencapai Kesepakatan Bahwa Melakukan Arisan Dengan Jumlah Peserta Dan Cicilan Yang Harus Dibayarkan.Dilihat Dari Penjelasan Rukun Akad Qardh Di Atas Dapat Disimpulkan Bahwa, Transaksi Arisan Kurban Di Mesjid Al-Hadi Sholihin Cibaduyut Kota Bandung Sudah Sesuai Dengan Prinsip Hukum Islam Karena Rukun Dan Syarat Sahnya Telah Terpenuhi.

Menurut Analisis Penulis Bahwa Akad Qardh Dalam Praktik Arisan Kurban Di Mesjid Al-Hadi Sholihin Cibaduyut Kota Bandung Adalah Sah Dan Telah Memenuhi Rukun Dan Syarat Sah Akad Qardh. Akad Dilakukan Harus Sesuai Dengan Kesepakatan Di Awal Akad Yang Berdasarkan Q.S Al-Maidah Ayat 1 :

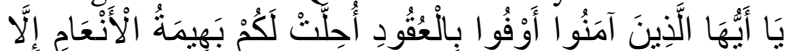

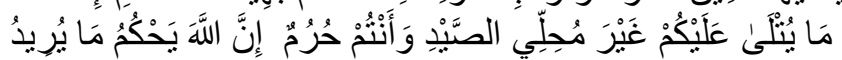

Artinya : Hai Orang-Orang Yang Beriman Penuhilah Akad-Akad Itu, Dihalalkan Bagimu Binatang Ternak, Kecuali Yang Akan Dibacakan Padamu. Yang Demikian Itu Yang Tidak Menghalalkan Berburu Ketika Kamu Sedang Mengerjakan Haji. Sesungguhnya Allah Menetapkan Hukum-Hukum Menurut Yang Di KehendakiNya.

Ayat Alquran Ini Dengan Tegas Memerintahkan Setiap Pelaku Kontrak Untuk Melaksanakan Dan Memenuhi Apa Yang Dijanjikan Dalam Kontrak JanjiJanji Yang Telah Diucapkan Harus Dilaksanakan Dengan Benar Karna Dalam Sebuah Akad Dalam Islam Terdapat Asas Kerelaan Yang Harus Di Penuhi Oleh Pihak Yang Berakad. Dan Sesuai Dengan Q.S Al-Maidah Ayat 8 Yang Berbunyi :

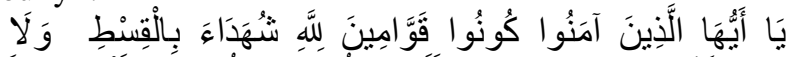

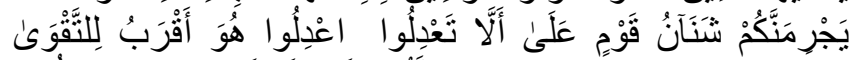

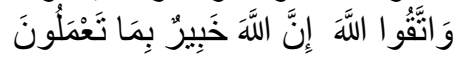

Artinya : Hai Orang-Orang Yang Beriman Hendaklah Kamu Jadi Orang-Orang Yang Selalu Menegakan Kebenaran Karena Allah, Menjadi Saksi Dengan Adil. Dan Janganlah Sekali-Kali Kebencianmu Terhadap Suatu Kaum Mendorong Kamu Untuk Berlaku Tidak Adil. Beralku Adilah Karena Adil Itu Lebih Dekat Dengan Taqwa. Dan Bertakwalah Kepada Allah Seseungguhnya Allah Maha Mengetahui Apa Yang Kamu Kerjakan.

Dalam Ayat Itu Sudah Jelas Yaitu Menuntut Para Pihak Yang Berakad Untuk Berlaku Benar Dalam Pengungkapan Kehendak Dan Keadaan, Dan Dapat Disimpulkan Bahwa Arisan Kurban Di Mesjid Al-Hadi Sholihin Tersebut Tidak Ada Unsur Komersial Atau Mencari Kuntungan. Tujuan Yang Terpenting Yang Ingin Dicapai Oleh Anggota Adalah Untuk Menunaikan Ibadah Kurban, Akad Ini Sudah Memenuhi Rukun Dan Syarat Qardh, Jadi Boleh Dilakukan Karena Tidak Bertentangan Dengan Hukum Islam

\section{KESIMPULAN}

1. Arisan Hukumnya Boleh Karena Pada Hakikatnya Arisan Merupakan Akad Ariyah, Yaitu Akad Pinjam Meminjam Lebih Tepatnya Akad Al-Qard/Al-Qiradh Yaitu Utang Piutang. Selain Itu Juga Merupakan Bentuk Akad Yang Didasarkan Pada Prinsip Taawun Yaitu Tolong Menolong.

2. Pelaksanaan Arisan Kurban Di Mesjid Al-Hadi Sholihin Cibaduyut Kecamatan Bojongloa Kidul Berdasarkan Pembentukan Akadnya Melalui UtangPiutang Yang Mana Dalam Fiqih Muamalah Dikenal Dengan Akad Qard Yang Dilakukan Secara Lisan Kemudian Dikuatkan Dengan Tulisan.

3. Arisan Kurban Mesjid Al-Hadi Sholihin Cibaduyut Kecamatan Bojongloa Kidul Sah Dan Boleh Dilaksanakan. Akad Dalam Arisan Kurban Mesjid AlHadi Sholihin Cibaduyut Kecamatan Bojongloa Kidul Menggunakan Akad Utang Piutang (Qard), Akad Ini Sudah Memenuhi Rukun Dan Syarat Qardh , Jadi Boleh Dilakukan Karena Tidak Bertentangan Dengan Hukum Islam.

\section{DAFTAR PUSTAKA}

[1] Basyir, A. A. (1993). Azas-Azas Muamalat. Yogyakarta: UII.

[2] Departemen Agama RI. Al-Qur'an Tajwid\&Terjemahan, Bandung:CV. Penerbit Diponegoro.

[3] Ghazali, A. R. (2010). Fiqh Muamalat. Jakarta: Kencana Prenada Media Group.

[4] Huda, N. (2015). Fiqih Muamalah. Semarang: CV Karya Abadi Jaya.

[5] Masadi, G. A. (2011). Fiqh Muamalah Konstektual. Jakarta: PT. Raja Grafindo Persada.

[6] Matdawam, M. N. (1980). Pengantar Ibadah Praktis. Yogyakarta: Kota Kembang.

[7] Rahmat, J. (1996). Islam Aktual: Refleksi Social Seseorang Cendikiawan Muslim, Cetetakan I. IX. Bandung: Mizan.

[8] Supramono, G. (2013). Perjanjian Utang Piutang. Jakarta: Kencan. 